\title{
Violencia sexual como mecanismo de represión y violación de los derechos humanos en el contexto de las protestas del año 202I en Colombia
}

\author{
Esneider Medina Claros a
}

Resumen - Este artículo de reflexión de carácter jurídico es producto de la investigación documental en prestigiosas fuentes de información sobre la violencia sexual como una forma de tortura y mecanismo de represión y violación de los derechos humanos en las protestas del año 202 I en Colombia. Tiene la finalidad de exponer los antecedentes, el contexto de la represión estatal, la protección jurídica internacional y constitucional de la libertad de expresión en marco del derecho a la protesta social y las obligaciones del Estado colombiano para la garantía y cumplimiento de los derechos humanos de acuerdo con las exigencias internacionales.

Palabras clave - Violencia Sexual, Represión, Libertad de Expresión, Protestas Sociales, Derechos Humanos.

Abstract - This legal reflection article is the product of documentary research in prestigious sources of information on sexual violence as a form of torture and a mechanism of repression and violation of human rights in the protests of 2021 in Colombia. Its purpose is to expose the antecedents, the context of state repression, the international and constitutional legal protection of freedom of expression within the framework of the right to social protest and the obligations of the Colombian State for the guarantee and fulfillment of the human rights of according to international requirements.

Keywords - Sexual Violence, Repression, Freedom of Expression, Social Protests, Human Rights.

\section{CÓMO CITAR}

HOW TO CITE:

Medina-Claros, E. (202I).

Violencia sexual como mecanismo de represión y violación de los derechos humanos en el contexto de las protestas del año 202I en Colombia. Interconectando Saberes, (12), 49-62. https://doi.org/10.25009/is.v0il 2 .2706

Recibido: 25 de mayo de 2021 Aceptado: I de julio de 202 I Publicado: 20 de julio de 2021

a Universidad de la Amazonia, Colombia. E-mail: emancros@gmail.com 


\section{INTRODUCCIÓN}

El 28 de abril de 202I iniciaron unas series de protestas y manifestaciones inéditas de inconformismo y rechazo social en Colombia contra las medidas y propuestas del Gobierno Nacional en cabeza del Presidente de la República Iván Duque Márquez. Las manifestaciones tuvieron su origen en la propuesta de reforma tributaria número 594/202I Senado y 439/202 I Cámara, también llamada estratégicamente como proyecto de "Ley de Solidaridad Sostenible" presentado por el anterior Ministro de Hacienda y Crédito Público, Alberto Carrasquilla. La propuesta fiscal resultó ser inoportuna, regresiva e impopular principalmente por tres razones: $\mathrm{I}^{\mathrm{a}}$ ) la extensión del IVA a más bienes y servicios; $2^{a}$ ) el gravamen a la canasta familiar y $3^{a}$ ) la ampliación de la base tributaria.

Debido al fuerte rechazo público de los colombianos a la propuesta de reforma fiscal, el mandatario Iván Duque anunció el 2 de mayo de 202I el retiro del proyecto de reforma tributaria e invitó a presentar un nuevo proyecto para evitar la incertidumbre financiera. Un día después de este anuncio, el Ministro de Hacienda y Crédito Público presentó la renuncia al cargo. Posteriormente, el II de mayo de 2021, el Presidente manifestó que habrá gratuidad en la educación superior pública para las personas de los estratos I, 2 y 3 en el segundo semestre del año 2021.

Pese a lo anterior, las protestas continuaron, especialmente, en las principales ciudades del país. Esto indica que la propuesta de reforma tributaria solamente fue la punta del iceberg, o la gota que rebasó la copa, pues el descontento social también radica en temas como: la lucha contra la desigualdad social y económica, la renta básica universal, la eliminación de la brutalidad policial, el autoritarismo, el desempleo, la impunidad, el asesinato sistemático de líderes sociales y defensores de derechos humanos, la implementación del acuerdo de paz, la gratuidad en la educación superior, la corrupción, el reinicio de las aspersiones aéreas con glifosato, entre otros.

En el marco de este Paro Nacional se han presentado torturas, homicidios, detenciones arbitrarias, desapariciones, abuso y brutalidad policial (especialmente, por parte del Escuadrón Móvil Antidisturbios -ESMAD- de la Policía Nacional). Pero, el delito o violación a los derechos humanos básicos que más indignación e ira colectiva ha causado es la violencia sexual, especialmente contra las mujeres y personas con orientación sexual diversa. Todos estos crímenes son graves violaciones a los derechos humanos como represalia estatal por ejercer los derechos a la libertad de expresión y de opinión, a la libertad de reunión, a libertad de asociación, a la huelga y a la protesta social.

El caso que más conmocionó a la nación fue el de la menor Alison Lizeth Salazar Miranda, quien antes de suicidarse, denunció el I 3 de mayo de 202 I en horas de la noche a través de su perfil de Facebook bajo el nombre de Alison Ugus que fue arbitrariamente detenida y abusada sexualmente por cuatro policías del ESMAD en la ciudad de Popayán, Colombia. Este suceso despertó de nuevo la rabia e indignación nacional, fuerte críticas, acusaciones y rechazo de la comunidad internacional y oenegés (ONG) defensoras de derechos humanos contra la gravísima represión del gobierno de Iván Duque y la violencia descomunal de la Fuerza Pública que está bajo su dirección y mando.

Una vez visto el contexto general, en este artículo de reflexión derivado de la investigación académica relevante en fuentes serias y de gran prestigio 
nacional e internacional, se expone la problemática de violencia sexual como mecanismo de represión y violación de los derechos humanos en el contexto de las protestas del año 202I en la República de Colombia y emitir unas conclusiones reflexivas al respecto. En este texto se aborda los antecedentes recientes de la brutalidad y violencia sexual policial en Colombia contra civiles protestantes, calificación jurídica de violencia sexual como tortura, los principales instrumentos internacionales que condenan la violencia policial y protegen la libertad de expresión y la protesta social, consagración de libertad de expresión y la protesta en la Constitución colombiana, obligaciones internacionales del Estado colombiano respecto a la garantía y materialización de estos y otros derechos humanos interdependientes. Finalmente, se presentan unas conclusiones con carácter reflexivo, crítico y propositivo sobre el tema.

\section{ANTECEDENTES RECIENTES DE LA BRUTALIDAD Y VIOLENCIA SEXUAL CONTRA MANIFESTANTES}

Existieron dos hechos históricos que fueron los antecedentes de la brutalidad y violencia policial que experimenta Colombia en el año 2021: I) el Paro Nacional de 2019 y 2) las Protestas del 9 y 10 de septiembre del 2020.

\section{Violencia Policial en el Paro Nacional de 2019}

Desde los primeros días del mes de octubre del año 2019 varias organizaciones sindicales, estudiantiles, indígenas, ambientalistas, campesinas, comunidad sexualmente diversa, pacifistas, entre otras, convocaron un Gran Paro Nacional que iniciaría el 21 de noviembre de 2019 contra lo que denominaron "el Paquetazo de Duque" que se traducía en las propuestas de reforma laboral, tributaria y pensional, lideradas por el partido de Gobierno, el Centro Democrático. Fueron varios días de manifestaciones y movilizaciones de rechazo a las medidas y propuestas del Ejecutivo Nacional.

Durante las protestas del año 2019 se registraron gravísimas violaciones a los derechos humanos con la finalidad estatal de reprimir y detener las manifestaciones y el ejercicio de los derechos a la libertad de expresión y de opinión, a la libertad de reunión y asociación y el derecho a la huelga. Así, lo denunciaron la Organización Mundial contra la Tortura (OMCT) y la Coalición Colombiana contra la Tortura (CCCT) en su informe titulado Protestas sociales y uso excesivo de la fuerza en Colombia: un análisis desde la lente de la prohibición de la tortura:

Pese a la existencia de las herramientas normativas internacionales y nacionales anteriormente mencionadas para regular el uso de la fuerza del ESMAD y de la fuerza pública en los escenarios de protesta, se han presentado graves violaciones de derechos humanos en las jornadas de movilización del Paro nacional. (2020, pág. 23).

En cuento a los asesinatos a manos de la Policía Nacional la ONG Temblores informó:

Al analizar las cifras, encontramos que el número de asesinatos cometidos presuntamente por la Policía Nacional en el territorio colombiano es consistente durante los años 2017, 2018 y 2019. De los 289 homicidios cometidos por esta fuerza pública, 97 ocurrieron en 2017, 103 en 2018 y 89 en 2019. Podríamos decir, entonces, que, en promedio, la Policía cometió un asesinato cada 
3.8 días y casi dos asesinatos por semana (Bolillo, Dios y Patria, 202I).

El caso más emblemático de asesinato ocurrido en el centro de Bogotá ejecutado por un agente del Estado fue el de Dilan Cruz, joven estudiante de bachillerato. Este hecho fue dictaminado como homicidio por el Instituto Nacional de Medicina Legal y Ciencias Forenses y cometido por el agente número 003478 del ESMAD, Manuel Cubillos Rodríguez, quien le disparó a la víctima un proyectil de kevlar (cartucho bean bag) con balines adentro usando una escopeta calibre 12.

De igual manera, varias organizaciones denunciaron detenciones arbitrarias, torturas; tratos crueles, inhumanos o degradantes, humillaciones y violencia sexual perpetrada por la Fuerza Pública, especialmente, por el ESMAD de la Policía Nacional.

La violencia sexual policial se presentó especialmente contra mujeres durante las protestas de 2019. Al respecto la Organización Mundial contra la Tortura (OMCT) y la Coalición Colombiana contra la Tortura (CCCT), declararon:

También se han registrado numerosos casos de uso excesivo de la fuerza contra las mujeres sin atender a los principios de proporcionalidad, racionalidad, necesidad y oportunidad por parte de miembros del ESMAD que, según el informe del Relator ante la ONU, se configuran como Tortura o TCID, toda vez que, se hace uso de la brutalidad policial para conseguir un determinado fin por medio de la fuerza. El periódico El Tiempo logró documentar la patada propinada por este escuadrón a una mujer que se encontraba en una situación de indefensión y que resultó gravemente lesionada física y psicológicamente. Este tipo de acciones, más las identificadas en los escenarios de detenciones arbitrarias contra las mujeres (humillaciones sexuales, amenazas, hostigamientos, entre otras.), permiten afirmar que existe un componente misógino en las prácticas de la fuerza pública. (2020, pp.25-26)

También la violencia sexual por agentes de seguridad del Estado colombiano se ha ejercido contra la población LGBT (grupo de personas con orientación sexual diversa). Según la publicación Más que cifras. Informe de derechos humanos de personas LGBT en Colombia 2019 de la organización Colombia Diversa:

En Colombia, la violencia contra personas LGBT defensoras de derechos humanos persiste, aún después de la firma del Acuerdo de Paz entre el Gobierno y la antigua guerrilla de las FARC-EP. Entre el 2017 y 2019, Colombia Diversa registró ataques contra $12 \mathrm{I}$ personas LGBT defensoras de derechos humanos en 22 departamentos del país. El $84 \%$ de los casos registrados corresponden a amenazas y hostigamientos, el $10,74 \%$ son homicidios y el resto corresponde a procedimientos policivos irregulares, tratos crueles, inhumanos o degradantes, $y$ actos de violencia sexual. (Colombia Diversa, 202I).

De esta forma se puede apreciar que en el año 2019 existieron casos de violencia sexual, especialmente contra las mujeres y personas LGBT, perpetrados por la Policía Nacional de Colombia, principalmente por el ESMAD, en el marco de las protestas sociales que se desarrollaron en el país. 


\section{Las Protestas del 9 y 10 de septiembre de 2020}

En la madrugada del 9 de septiembre de 2020 fue asesinado el estudiante de Derecho e ingeniero Javier Ordoñez a manos de dos patrulleros de la Policía Nacional en medio de un procedimiento por violación de la cuarentena decretada debido a la pandemia del Covid-19. Durante el violento operativo los uniformados le propinaron varias descargas eléctricas con una pistola taser a Javier Ordoñez, lo asfixiaron, lo trasladaron al Centro de Atención Inmediata (CAI) del barrio Villa Luz de la localidad de Engativá en Bogotá y lo siguieron torturando sin piedad hasta provocarle la muerte.

Ese hecho de brutalidad policial, registrado en video y viralizado por usuarios las redes sociales como Facebook y medios masivos de comunicación, generó estupor, rechazo y gran indignación de la población nacional, especialmente, en ciudades capitales como Bogotá, Cali, Medellín, Barranquilla, Santa Marta, Cúcuta, Ibagué y Neiva. Según la cadena de información internacional France 24, el siguiente fue el saldo de las protestas del 9 y 10 de septiembre de 2020 contra la violencia policial:

Al menos 10 fallecidos, de entre 17 y 27 años, $y$ más de 400 heridos entre oficiales y civiles dejan las dos noches de protestas en varias ciudades colombianas contra la brutalidad policial. Los enfrentamientos iniciaron tras la muerte de Javier Ordoñez a manos de dos policías que usaron varias veces una pistola taser (2020).

En lo que respecta a la violencia sexual como mecanismo de represión de la protesta y libertad de expresión perpetrada por la Fuerza Pública, especialmente por la Policía Nacional, según informó la
Oficina en Colombia del Alto Comisionado de las Naciones Unidas para los Derechos Humanos (ACNUDH) "se conocieron dos situaciones que presuntamente involucrarían a miembros de policía en actos de violencia sexual durante las protestas y que habrían ocurrido en dos Comandos de Atención Inmediata" (2020, p.8).

En el segundo día de protestas de septiembre de 2020 varias mujeres denunciaron que fueron víctimas de violencia sexual por parte de la Policía Nacional según "se conoció que tres mujeres habrían sido víctimas de abuso sexual presuntamente por parte de uniformados, el pasado 10 de septiembre, en el CAI de San Diego, en el centro de la ciudad" (Radio Nacional de Colombia, 2020).

Respecto a la práctica criminal, represiva y cruel de violencia sexual por la Fuerza Pública para repeler y detener la protesta social en una publicación del medio de comunicación digital Cerosetenta de la Universidad de los Andes se concluye que:

Estas violencias, aunque recrudecidas el 9 y 10 de septiembre de este año, no se pueden considerar aisladas. De acuerdo con una investigación adelantada por la ONG Temblores, desde la implementación del nuevo código de Policía, en el año 2017, han empezado a detectar sistematicidad en violencias que incluyen: violencia física, sexual y homicida. Entre 2017 y 2019 se presentaron 24I denuncias por abuso sexual, donde el mayor perpetrador es la Policía, seguida muy de cerca por el Ejército. El $74 \%$ de las víctimas son mujeres, la mayoría estudiantes, y Bogotá es la ciudad que concentra más denuncias. El otro grupo más vulnerable, según el informe de 
Temblores, son las mujeres consumidoras de sustancias psicoactivas (2020).

El mismo medio de periodismo aseguró que Tembrores ONG documentó varios casos de violencia sexual cometidos por las Fuerza Pública, aunque hay muchos que faltan por confirmar. De igual manera, sostuvo que según la misma ONG muchos de estos hechos delictivos han se incrementado en las instalaciones de los cuerpos de seguridad del Estado colombiano:

En lo que va del 2019 y el 2020, Temblores ha documentado 54 casos de violencia sexual cometidos por miembros de la Fuerza Pública, pero aseguran que tienen varios casos en proceso de confirmación. Mientras que en 2017 y 2018 la mayoría de las denuncias se concentraban en espacios domésticos de las víctimas, desde el 2019, la organización ha encontrado un aumento de casos que ocurren en guarniciones militares y policiales (Cerosetenta de la Universidad de los Andes, 2020).

De lo expuesto, se colige que en las protestas sociales de septiembre de 2020 se presentaron múltiples casos de violencia sexual sistemática y generalizada, particularmente contra mujeres y personas LGBT, por parte de la Fuerza Pública. Estas prácticas son gravísimas violaciones a los derechos humanos $y$ deben desaparecer en un Estado Social y Democrático de Derecho como se dice llamar la República de Colombia.

A modo de cierre de este capítulo, se puede aseverar que la violencia sexual como mecanismo de represión y violación de los derechos humanos en Colombia durante las protestas del año 2021 tuvieron sus antecedentes recientes en dos sucesos: $1^{\circ}$ ) la brutalidad policial durante las manifestaciones $y$ movilizaciones sociales del año 2019 y $2^{\circ}$ ) las protestas del 9 y 10 de septiembre de 2020. El primero tuvo su causa en el rechazo a las propuestas de reforma laboral, pensional y tributaria del Gobierno Nacional liderado por el Presidente Iván Duque y el segundo; en un hecho de violencia y abuso policial registrado en Bogotá, Distrito Capital, que conmocionó y movilizó a los ciudadanos colombianos en señal de repudio al abuso de poder y brutalidad de la Fuerza Pública, en particular, la violencia contra civiles perpetrada por la Policía Nacional.

\section{VIOLENCIA SEXUAL COMO TORTURA Y MECANISMO DE REPRESIÓN}

Varias cortes internacionales han considerado la violencia sexual como una forma de tortura que los Estados deben prevenir, sancionar y erradicar. Por ejemplo, la Corte Interamericana de Derechos Humanos en una sentencia contra el Estado mexicano, concluyó:

(...) esta Corte considera que una violación sexual puede constituir tortura aun cuando consista en un solo hecho u ocurra fuera de instalaciones estatales, como puede ser el domicilio de la víctima. Esto es así ya que los elementos objetivos y subjetivos que califican un hecho como tortura no se refieren ni a la acumulación de hechos ni al lugar donde el acto se realiza, sino a la intencionalidad, a la severidad del sufrimiento y a la finalidad del acto, requisitos que en el presente caso se encuentran cumplidos (Caso Fernández Ortega y otros vs. México, 2010). 
Como se puede apreciar en ese caso judicial, para la calificación jurídica de la violencia sexual como tortura la Corte IDH se basó en la intencionalidad en cabeza del perpetrador de realizar el comportamiento delictivo, la severidad del sufrimiento infligido a la víctima y la finalidad que se tiene con la ejecución el acto criminal. En cuanto a este último elemento ese tribunal internacional "considera que, en términos generales, la violación sexual, al igual que la tortura, persigue entre otros, los fines de intimidar, degradar, humillar, castigar o controlar a la persona que la sufre" (Caso Fernández Ortega y otros vs. México, 2010).

Respecto a la violencia sexual como mecanismo de represión y dispersión de la protesta social, en otro caso más reciente, la misma corte internacional concluyó:

(...) en el presente caso, los agentes policiales instrumentalizaron los cuerpos de las mujeres detenidas como herramientas para transmitir su mensaje de represión y desaprobación de los medios de protesta empleados por los manifestantes. Cosificaron a las mujeres para humillar, atemorizar e intimidar las voces de disidencia a su potestad de mando. La violencia sexual fue utilizada como un arma más en la represión de la protesta, como si junto con los gases lacrimógenos y el equipo anti-motín, constituyeran sencillamente una táctica adicional para alcanzar el propósito de dispersar la protesta y asegurarse de que no volviera a cuestionarse la autoridad del Estado. Este tipo de conductas en el mantenimiento del orden público, más que reprochable, es absolutamente inaceptable (Caso Mujeres Víctimas de Tortura Sexual en Atenco Vs. México, 2018).
Como consecuencia de lo expuesto, se afirma, más allá de toda duda, que la violencia sexual es una forma de tortura de acuerdo la jurisprudencia supranacional desarrollada por diversos tribunales encargados de aplicar e interpretar el Derecho Internacional de los Derechos Humanos. Este tipo de violencia infligidas por los cuerpos de seguridad del Estado cuando se emplea como arma para la represión y dispersión de la protesta social se configura en una evidente y clara violación de los derechos humanos, especialmente contra los derechos a la integridad personal, vida privada, libertad personal, no ser sometido a tortura, libertad de asociación y de reunión, honra, dignidad y libertad de expresión y de opinión.

\section{VIOLENCIA SEXUAL PARA LA REPRESIÓN DE LAS PROTESTAS SOCIALES DEL AÑO 202I EN COLOMBIA}

En el marco del Paro Nacional de 202I "la ONG Temblores ha registrado, entre el 28 de abril y el 18 de mayo, 27 denuncias de hechos de violencia sexual y de género" (Cardoso, 202I).

El caso más emblemático y que generó más indignación nacional fue el de la menor Alison Lizeth Salazar Miranda, quien denunció el I 3 de mayo de 202 I en su red social Facebook con el nombre de perfil Alison Ugus haber sido víctima de abuso sexual por cuatro miembros de la Policía Nacional en medio de las protestas que se registraban en la ciudad de Popayán, Cauca:

Les tocó cogerme entre 4 no Hijueputas?? Yo soy a la que cogieron, en ningún momento me ven tirando piedras, no iba con ellos, me dirigía hacia la casa de un amigo que me dejaría quedar en su casa, cuando menos pensé estaban 
encima, ni siquiera corrí porque era peor, lo único que hice fue esconderme detrás de un muro, y solo porque estaba grabando me cogieron, en medio de eso me bajaron el pantalón y me manosearon hasta el alma, en el video queda claro que yo les digo que me suelten porque me estaban "desnudando" quitando el pantalón.

Pero casi les da un mal cuando me revisaron los documentos y se dieron cuenta que soy hija de un policía, apoyo totalmente el paro y las manifestaciones, pero ayer NO ESTABA CON LOS DE LAS MARCHAS (Miranda, 202I).

Frente a ese dramático caso la $\mathrm{CIDH}$ se pronunció mediante su cuenta de Twitter:

La @CIDH condena enérgicamente los hechos de violencia sexual y psicológica contra mujeres adolescentes, presuntamente cometidos por integrantes de la Policía Nacional en el contexto de las manifestaciones en Popayán (CIDH, 202I).

La Comisión también recordó a través de la misma red social que "la violencia sexual cometida por agentes estatales, en abuso de su poder y aprovechando la vulnerabilidad de la víctima, es una forma de tortura" (CIDH, 202I).

Finalmente, se llega a la conclusión que la violencia sexual perpetrada por la Fuerza Pública, especialmente por la Policía Nacional de Colombia, en el marco de las protestas del año 2021, configura una forma de tortura que se ha utilizado y sigue siendo usada como mecanismo de represión, dispersión y control de los manifestantes y para castigar, humillar, intimidar y disuadir a las personas que ejercen los derechos a la libertad de expresión y de opinión, a libertad de reunión y asociación y la huelga en medio de una sociedad que se ha declarado formal y jurídicamente como democrática, pero que materialmente, no podría considerarse plena y ampliamente, como una democracia debido al abuso de poder gubernamental y estatal y a la sistemática violación de los derechos humanos.

\section{PRINCIPALES INSTRUMENTOS}

INTERNACIONALES QUE PROTEGEN LA LIBERTAD DE EXPRESIÓN Y LA PROTESTA SOCIAL EN LAS AMÉRICAS

Los principales instrumentos que protegen la libertad de expresión y la protesta social en las Américas son: la Declaración Universal de Derechos Humanos, el Pacto Internacional de Derechos Civiles y Políticos, Convención sobre los Derechos del Niño, Convención Americana sobre Derechos Humanos, Declaración Americana de los Derechos y Deberes del Hombre, Declaración de Principios sobre Libertad de Expresión y la Carta Democrática Interamericana.

La Convención Americana sobre Derechos Humanos (CADH), principal instrumento de carácter internacional del Sistema Interamericano Sistema Interamericano de Derechos Humanos (SIDH), en su artículo 13 consagra el derecho a la libertad de pensamiento y de expresión:

Toda persona tiene derecho a la libertad de pensamiento y de expresión. Este derecho comprende la libertad de buscar, recibir y difundir informaciones e ideas de toda índole, sin consideración de fronteras, ya sea oralmente, por escrito o en forma impresa o 
artística, o por cualquier otro procedimiento de su elección (Organización de los Estados Americanos, 1969).

El mismo art. 13 de la CADH prohíbe restringir el derecho de expresión por vías o medios indirectos:

No se puede restringir el derecho de expresión por vías o medios indirectos, tales como el abuso de controles oficiales o particulares de papel para periódicos, de frecuencias radioeléctricas, o de enseres y aparatos usados en la difusión de información o por cualesquiera otros medios encaminados a impedir la comunicación y la circulación de ideas y opiniones (Organización de los Estados Americanos, (969).

Por su importancia para una sociedad democrática, la Organización de los Estados Americanos (OEA) mediante el art. $4^{\circ}$ de la Carta Democrática Interamericana reconoce la libertad de expresión como componente esencial para la democracia:

Son componentes fundamentales del ejercicio de la democracia la transparencia de las actividades gubernamentales, la probidad, la responsabilidad de los gobiernos en la gestión pública, el respeto por los derechos sociales y la libertad de expresión y de prensa (Organización de los Estados Americanos, 200I).

En el mismo sentido la Declaración de Principios sobre Libertad de Expresión reconoce la libertad de expresión como derecho fundamental y condición necesaria para la existencia de la democracia (principio $\left.1^{\circ}\right)$ :

La libertad de expresión, en todas sus formas y manifestaciones, es un derecho fundamental e inalienable, inherente a todas las personas. Es, además, un requisito indispensable para la existencia misma de una sociedad democrática (Organización de Estados Americanos, 2000).

El mismo instrumento internacional en su principio $1 \mathrm{I}^{\circ}$, declara que los servidores públicos están sometidos a mayor escrutinio social y no se debe penalizar las expresiones ofensivas contra tales funcionarios producto de ese legítimo ejercicio social:

Los funcionarios públicos están sujetos a un mayor escrutinio por parte de la sociedad. Las leyes que penalizan la expresión ofensiva dirigida a funcionarios públicos generalmente conocidas como "leyes de desacato" atentan contra la libertad de expresión y el derecho a la información (Organización de Estados Americanos, 2000).

Antes de finalizar este acápite resulta importante resaltar que, para el ejercicio de los derechos humanos interconectados a la libertad de expresión, a la libertad de reunión y de asociación y a la protesta social, no se requiere de permiso previo por parte de las autoridades. Pues, la exigencia permisos por parte del Estado para el ejercicio pleno de los mencionados derechos resulta contraria al Sistema Interamericano de Protección de Derechos Humanos:

La CIDH ha considerado que el ejercicio del derecho de reunión a través de la protesta social no debe sujetarse a una autorización por parte de las autoridades $\mathrm{ni}$ a requisitos excesivos que dificulten su realización. Los requisitos jurídicos que sientan una base para que una reunión o manifestación sea prohibida - limitada como, por ejemplo, a través de la 
exigencia de un permiso previo, no son compatibles con el derecho de reunión ni con el ejercicio de la libertad de expresión en el Sistema Interamericano (Relatoría Especial para la Libertad de Expresión de la CIDH, 2019, p.27).

Siendo así el panorama normativo de protección a la libertad de expresión y de opinión en el marco de la protesta social dentro del Sistema Interamericano de Derechos Humanos, se tiene que existen varias normas internacionales protegen estos derechos en Latinoamérica, entre las cuales se destacan: la Convención Americana sobre Derechos Humanos, Pacto Internacional de Derechos Civiles y Políticos, la Carta Democrática Interamericana y la Declaración de Principios sobre Libertad de Expresión.

\section{CONSAGRACIÓN DE LIBERTAD DE EXPRESIÓN Y LA PROTESTA EN LA CONSTITUCIÓN COLOMBIANA}

La Constitución Política de la República de Colombia consagra en su art. 20 la libertad de expresión. Según la norma constitucional "Se garantiza a toda persona la libertad de expresar y difundir su pensamiento y opiniones, la de informar y recibir información veraz e imparcial, y la de fundar medios masivos de comunicación" (Asamblea Nacional Constituyente, 199I). Para Diana Marcela Peña Cuellar y Astrid Daniela Vidal Lasso, investigadoras y profesoras de Derecho de la Universidad de la Amazonia, dicho artículo "trae consigo una protección en cuatro órbitas: i) Libertad de expresar y difundir opiniones, ii) Informar y recibir información, iii) Fundar medios de comunicación y iv) la no censura" (2020, p.45).
A su vez, referente al derecho a la protesta social el artículo 37 del Texto constitucional colombiano establece que "Toda parte del pueblo puede reunirse y manifestarse pública y pacíficamente" (Asamblea Nacional Constituyente, 1991).

Finalmente, hay que decir que la Constitución colombiana también reconoce y consagra otros derechos humanos estrechamente relacionados con la libertad de expresión y el derecho a la protesta como la libertad de locomoción, la libertad de asociación, la participación política y el derecho a la huelga, establecidos en los artículos 24, 38, 40 y 56 de la Carta Magna.

\section{NORMAS INTERNACIONALES SOBRE EL USO DE LA FUERZA Y QUE CONDENAN LA VIOLENCIA POLICIAL EN LAS PROTESTAS}

Una vez expuestos los principales instrumentos internacionales que consagran y protegen la libertad de expresión y de opinión en el marco del derecho a la protesta, en este acápite se hace una breve enunciación e interpretación de la principal normatividad internacional sobre el uso de la fuerza y que condena la violencia policial, incluida la violencia sexual, como violación de los derechos humanos en contextos de protestas sociales.

Los primordiales instrumentos de la normatividad internacional sobre el uso de la fuerza y que sancionan la violencia y brutalidad policial son: el Código de Conducta para los Funcionarios Encargados de Cumplir la Ley, el Conjunto de Principios para la Protección de Todas las Personas Sometidas a Cualquier Forma de Detención o Prisión, los Principios Básicos sobre el Empleo de la Fuerza y de Armas de Fuego por los Funcionarios Encargados de Hacer Cumplir la Ley, la 
Convención contra la Tortura y Otros Tratos o Penas Crueles, Inhumanos o Degradantes; la Convención Americana de Derechos Humanos, el Pacto Internacional de Derechos Civiles y Políticos, la Convención Interamericana para Prevenir y Sancionar la Tortura y la Convención Interamericana para Prevenir, Sancionar y Erradicar la Violencia contra la Mujer.

En el Sistema Universal de Protección de los Derechos Humanos (SUDH) está proscrita toda forma de tortura u otros tratos o penas crueles, inhumanos o degradantes:

Ningún funcionario encargado de hacer cumplir la ley podrá infligir, instigar o tolerar ningún acto de tortura $\mathrm{u}$ otros tratos o penas crueles, inhumanos o degradantes, ni invocar la orden de un superior o circunstancias especiales, como estado de guerra o amenaza de guerra, amenaza a la seguridad nacional, inestabilidad política interna, o cualquier otra emergencia pública, como justificación de la tortura u otros tratos o penas crueles, inhumanos $\circ$ degradantes (Asamblea General de las Naciones Unidas, 1979).

Según las Asamblea General de la ONU, la utilización de la fuerza y armas de fuegos por los funcionarios encargados de hacer cumplir la ley se debe evitar y limitar al mínimo necesario:

Al dispersar reuniones ilícitas, pero no violentas, los funcionarios encargados de hacer cumplir la ley evitarán el empleo de la fuerza o, si no es posible, lo limitarán al mínimo necesario.

Al dispersar reuniones violentas, los funcionarios encargados de hacer cumplir la ley podrán utilizar armas de fuego cuando no se puedan utilizar medios menos peligrosos $y$ únicamente en la mínima medida necesaria. Los funcionarios encargados de hacer cumplir la ley se abstendrán de emplear las armas de fuego en esos casos, salvo en las circunstancias previstas en el principio 9 (Asamblea General de la ONU, 1990).

La misma Organización de las Naciones Unidas (ONU) reconoce que "todas las personas están autorizadas a participar en reuniones lícitas y pacíficas, de conformidad con los principios consagrados en la Declaración Universal de Derechos Humanos y en el Pacto Internacional de Derechos Civiles y Políticos" (1990).

La Asamblea General de la ONU también prohibió la tortura, tratos o penas crueles inhumanos o degradantes contra las personas sometidas a cualquier forma de detención o prisión. En consecuencia, "No podrá invocarse circunstancia alguna como justificación de la tortura $\circ$ de otros tratos $\circ$ penas crueles, inhumanos o degradantes" (1988).

Así las cosas, se puede evidenciar que tanto en el Sistema Universal de Protección de Derechos Humanos (SUDH), nacido en el seno de Naciones Unidas, como en el Sistema Interamericano de Derechos Humanos (SIDH) de la OEA, existen diversas normas y principios jurídicos internacionales que buscan evitar al máximo el uso de la fuerza y limitarla al mínimo necesario por parte de las autoridades encargadas de hacer cumplir la ley en los distintos Estados. Por consiguiente, es correcto afirmar que a la luz de la normatividad internacional el uso excesivo de la fuerza; la tortura, tratos $\circ$ penas crueles inhumanos $\circ$ degradantes (incluida, la violencia sexual), detenciones arbitrarias; asesinatos, desapariciones y otras formas de 
abuso de poder por parte de la Fuerza Pública, particularmente por la Policía Nacional de Colombia, están prohibidas y deben ser castigadas, pues las mismas prácticas constituyen una abierta, sistemática, clara y gravísima violación a los derechos humanos, máxime cuando se realizan en situaciones de reclamación colectiva de derechos, como lo son las protestas sociales.

\section{OBLIGACIONES INTERNACIONALES DEL ESTADO COLOMBIANO PARA GARANTIZAR EL PLENO EJERCICIO DE LA PROTESTA SOCIAL}

Para la Comisión Interamericana de Derechos Humanos ( $\mathrm{CIDH})$ en contextos de protestas sociales el Estado tiene las "obligaciones de respetar, proteger y garantizar los derechos humanos" (Relatoría Especial para la Libertad de Expresión de la CIDH, 2019, p.II).

Por su parte, los investigadores jurídicos Enrique Prieto-Ríos y Juan Pablo Coy Jaramillo, manifestaron:

- El Estado debe abstenerse de violar cualquiera de los derechos humanos relacionados con la protesta y que están reconocidos por tratados internacionales.

- El Estado debe promover y proteger el derecho a la protesta y todos los derechos asociados. También implica que cuando el derecho se vea violado por un tercero, aquel sea debidamente restablecido.

- El Estado tiene la obligación de asegurar las condiciones necesarias para proteger este derecho. (Prieto-Ríos \& Coy Jaramillo, 2020).
Respecto a la criminalización de la protesta social la CIDH dijo:

La criminalización de la protesta social consiste en el uso del poder punitivo del Estado para disuadir, castigar o impedir el ejercicio del derecho a la protesta y en algunos casos, de la participación social y política en forma más amplia, mediante el uso arbitrario, desproporcional o reiterado de la justicia penal o contravencional en contra de manifestantes, activistas, referentes sociales o políticos por su participación en una protesta social, o el señalamiento de haberla organizado, o por el hecho de formar parte del colectivo o entidad organizadora o convocante (Relatoría Especial para la Libertad de Expresión de la CIDH, 20I9, p.64).

En cuanto al grupo de tipo penales para criminalizar el derecho a la protesta la misma Comisión expresó:

El conjunto de tipos penales aplicados para criminalizar presenta similitudes en los diferentes países de la región. Entre las figuras más habituales, se destacan: la obstrucción de vías públicas; la resistencia a la autoridad y los delitos de ultrajes y desacato; la perturbación a la paz pública o al orden público; la apología al delito; los daños al patrimonio público o privado; el sabotaje; la usurpación e invasión de inmueble; la asociación criminal e instigación a delinquir; la inducción a la rebelión; la sedición y el tumulto; el motín; la extorsión o la coacción agravada e, incluso, los tipos penales de terrorismo (Relatoría Especial para la Libertad de Expresión de la CIDH, 2019, p.66). 
Entonces, se sostiene que, para el pleno ejercicio del derecho a la protesta y demás derechos relacionados, el Estado colombiano tiene las obligaciones internacionales de respetar, proteger, promover, garantizar, facilitar la materialización de los derechos humanos y no criminalizar a los líderes y participantes de manifestaciones y protestas. También, tiene el deber de investigar, juzgar y sancionar a los responsables de las violaciones a los derechos humanos.

\section{CONCLUSIONES}

La violencia estatal perpetrada por la Fuerza Pública, especialmente por la Policía Nacional en el contexto de las protestas del año 202I en Colombia tuvieron sus antecedentes recientes en el Paro Nacional de 2019 y las manifestaciones públicas de rechazo social por el cruel asesinato policial de Javier Ordoñez en el mes de septiembre del año 2020. En dichas manifestaciones se registraron múltiples violaciones de los derechos humanos. Debido a la propuesta de reforma fiscal presentada por el Gobierno de Colombia el 28 de abril de 202 I se dio inicio a un histórico estallido social. La reforma tributaria fue la gota que rebasó la copa, puesto que los reclamos de la ciudadanía van desde la lucha contra brutalidad policial hasta la desigualdad social y económica que cada año es más evidente en el país.

La violencia sexual constituye una forma de tortura y un mecanismo de represión y violación de los derechos humanos que ha sido y continúa siendo utilizado por el Estado colombiano mediante la Fuerza Pública, específicamente por la Policía Nacional en el marco de las protestas sociales del año 202I se han registrado gravísimos casos de violencia sexual ejecutados por efectivos de la Policía para castigar, humillar, disuadir, degradar y dispersar a las personas que se manifiestan contra el Gobierno colombiano, principalmente contra mujeres y población LGBT.

La libertad expresión y el derecho a la protesta y demás asociados están claramente protegidos y reconocidos por instrumentos y principios de carácter internacional. La Constitución colombiana también consagra y reconoce dichos derechos humanos fundamentales.

Existen varias normas en el ámbito internacional que tienen la finalidad de evitar al máximo el empleo de la fuerza y limitarla al mínimo necesario por parte de los funcionarios encargados de hacer cumplir la ley. Dichas disposiciones también condenan la violencia policial y advierten que no podrá alegarse circunstancia alguna como justificación de la tortura u otros tratos o penas crueles, inhumanos o degradantes.

Según se colige del Derecho Internacional y los pronunciamientos de las organizaciones multilaterales el Estado colombiano debe cumplir con las obligaciones de respetar, proteger, promover, garantizar y facilitar la realización de los derechos humanos, no criminalizar a los manifestantes e investigar, juzgar y sancionar a los responsables de las violaciones a los derechos humanos para garantizar y materializar el pleno ejercicio del derecho a la protesta social.

Finalmente, es oportuno manifestar que el Gobierno colombiano debe escuchar el clamor ciudadano para que la construcción de una sociedad más democrática y justa. El jefe de Estado debe poner en marcha acciones que permitan el pleno y amplio cumplimiento de los derechos humanos y la prevención, sanción y eliminación de la tortura sexual y otras conductas contrarias a los estándares internaciones 
como mecanismos de represión y violación de los derechos humanos en situaciones de protestas sociales.

\section{REFERENCIAS}

Cerosetenta de la Universidad de los Andes. (16 de septiembre de 2020). El relato de una violencia sexual en una Estación de Policía.

https://cerosetenta.uniandes.edu.co/el-relato-deuna-violencia-sexual-en-una-estacion-de-policial

Colombia Diversa. (202I). Más que cifras. Informe de derechos humanos de personas LGBT https://colombiadiversa.org/c-diversa/wpcontent/uploads/2021/03/Mas-que-cifras.pdf

France 24. (I I de septiembre de 2020). Segunda noche de protestas en Colombia contra la brutalidad policial. https://www.france24.com/es/202009I Isegunda-noche-de-protestas-en-colombiacontra-la-brutalidad-policial

Oficina del Alto Comisionado para los Derechos Humanos. (2020). Situación de los derechos humanos en Colombia. Bogotá.

https://www.hchr.org.co/documentoseinformes/i nformes/altocomisionado/HRC46-Informe-anual2020 traduccion-no-oficial.pdf

Organización de Estados Americanos. (2 al 20 de octubre de 2000). Declaración de Principios sobre Libertad de Expresión. http://www.cidh.oas.org/Basicos/Basicos I 3.htm

Organización de los Estados Americanos. (7 al 22 de noviembre de 1969). Convención Americana sobre Derechos Humanos.

https://www.oas.org/dil/esp/tratados_b32 convencion_americana_sobre_derechos hu manos.htm

Organización de los Estados Americanos. (I I de septiembre de 200I). Carta Democrática Interamericana.

http://www.oas.org/OASpage/esp/Documentos/ Carta_Democratica.htm

Organización Mundial contra la Tortura (OMCT) y

Coalición Colombiana contra la Tortura

(CCCT). (2020). Protestas sociales y uso excesivo de la fuerza en Colombia: un análisis desde la lente de la prohibición de la tortura. Bogotá, Colombia. https://www.coljuristas.org/documentos/tmp/Pro testas $\% 20$ sociales $\% 20$ \%20CCCT\%200MCT\%20Junio2020.pdf

Radio Nacional de Colombia. ( 12 de septiembre de 2020). Cuarto día de protestas en Bogotá. https://www.radionacional.co/actualidad/cuartodia-de-protestas-en-bogota
Relatoría Especial para la Libertad de Expresión de la CIDH. (2019). Informe Anual 2019. Protesta y Derechos Humanos. Estándares sobre los derechos involucrados en la protesta social y las obligaciones que deben guiar la respuesta estatal. https://www.oas.org/es/cidh/expresion/publicacio nes/ProtestayDerechosHumanos.pdf

Temblores ONG. (202I). Bolillo, Dios y Patria. Bogotá. https://www.temblores.org/bolillo-dios-y-patria 